\title{
Abiotic stress-induced accumulation of raffinose in Arabidopsis leaves is mediated by a single raffinose synthase (RS5, At5g40390)
}

\author{
Aurélie Egert ${ }^{1,3}$, Felix Keller $^{1}$ and Shaun Peters ${ }^{2^{*}}$
}

\begin{abstract}
Background: The sucrosylgalactoside oligosaccharide raffinose (Raf, Suc-Gal ${ }_{1}$ ) accumulates in Arabidopsis leaves in response to a myriad of abiotic stresses. Whilst galactinol synthases (GolS), the first committed enzyme in Raf biosynthesis are well characterised in Arabidopsis, little is known of the second biosynthetic gene/enzyme raffinose synthase (RS). Conflicting reports suggest the existence of either one or six abiotic stress-inducible RSs (RS-1 to -6) occurring in Arabidopsis. Indirect evidence points to At5g40390 being responsible for low temperature-induced Raf accumulation in Arabidopsis leaves.

Results: By heterologously expressing At5g40390 in E.coli, we demonstrate that crude extracts synthesise Raf in vitro, contrary to empty vector controls. Using two independent loss-of-function mutants for At5g40390 (rs 5-1 and 5-2), we confirm that this RS is indeed responsible for Raf accumulation during low temperatureacclimation $\left(4^{\circ} \mathrm{C}\right)$, as previously reported. Surprisingly, leaves of mutant plants also fail to accumulate any Raf under diverse abiotic stresses including water-deficit, high salinity, heat shock, and methyl viologen-induced oxidative stress. Correlated to the lack of Raf under these abiotic stress conditions, both mutant plants lack the typical stress-induced RafS activity increase observed in the leaves of wild-type plants.
\end{abstract}

Conclusions: Collectively our findings point to a single abiotic stress-induced RS isoform (RS5, At5g40390) being responsible for Raf biosynthesis in Arabidopsis leaves. However, they do not support a single RS hypothesis since the seeds of both mutant plants still contained Raf, albeit at 0.5-fold lower concentration than seeds from wild-type plants, suggesting the existence of at least one other seed-specific RS. These results also unambiguously discount the existence of six stress-inducible RS isoforms suggested by recent reports.

Keywords: Abiotic stress, Arabidopsis, Galactinol, Raffinose, Raffinose synthase, Seeds, Water-soluble carbohydrates

\section{Background}

Raffinose synthase (RS, EC 2.4.1.82) is an important enzyme involved in the biosynthesis of the raffinose family oligosaccharides (RFOs; Suc- $[\mathrm{Gal}]_{\mathrm{n}}, 13<\mathrm{n} \geq 1$ ) which are $\alpha 1,6$-galactosyl extensions of sucrose (Suc) occurring frequently in higher plants. The first step in their biosynthesis is initiated by galactinol synthase (GolS, EC 2.4.1.123) which catalyses the formation of galactinol (Gol; 1-O- $\alpha$-D-galactopyranosyl-L-myo-inositol), using UDP-galactose (UDP-Gal) and myo-inositol (Ino) as sub-

\footnotetext{
* Correspondence: swpeters@sun.ac.za

${ }^{2}$ Institute for Plant Biotechnology, Department of Genetics, Faculty of AgriSciences, Stellenbosch University, Matieland 7602, South Africa Full list of author information is available at the end of the article
}

strates. The second step involves RS which transfers the galactosyl moiety from $\mathrm{Gol}$ to the $\mathrm{C}_{6}$ position of the glucose (Glc) moiety in Suc, forming an $\alpha 1,6$-galactosidic linkage to yield the trisaccharide raffinose (Raf, Suc$\mathrm{Gal}_{1}$ ). In a third step, stachyose synthase (SS, EC 2.4.1.67) transfers the galactosyl moiety from Gol to the $\mathrm{C}_{6}$ position of the Gal moiety in Raf to yield the tetrasaccharide stachyose (Sta, Suc- $\mathrm{Gal}_{2}$ ). Biosynthesis of higher RFO oligomers occurs via a Gol-independent biosynthetic pathway. In Ajuga reptans, galactan:galactan galactosyl transferase (GGT) utilizes RFOs as both galactosyl donors and acceptors during chain elongation, facilitating the synthesis of higher RFO oligomers (up to Suc-(Gal) ${ }_{13}$; [1-4]). GGT activity has also been reported to occur in leaves of Coleus blumei [5].

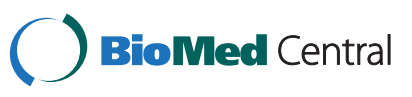


Plant RSs are generally poorly characterised and putative gene sequences have been reported for only a few plants, including pea, cucumber, maize, grape, rice and Arabidopsis [6]. To date, the only extensive biochemical characterisation of a RS has been reported from pea seeds [7], cucumber [8] and to a lesser degree from rice [9]. Arabidopsis is reported to contain six putative abiotic stress-inducible $R S$ genes $[R S 1-6,10]$. However, we have recently demonstrated that $R S 2$ (At3g57520/ATSIP2), contrary to being reported as an abiotic stress-inducible RS [10-12], is in fact a bona fide alkaline $\alpha$-galactosidase ( $\alpha-G a l,[13])$. Conversely, RS5 (At5g40390) is annotated as being similar to the $\alpha$-Gal ATSIP1, but evidence suggests that it is a RS [14]. Based on sequence similarity to the known pea RS, RS5 has also been suggested to be the only RS isoform in Arabidopsis [6]. In the absence of complete functional characterisation of the six putative RSs, their actual number in Arabidopsis is a matter of speculation.

In Arabidopsis vegetative tissues (leaves and roots), the only RFO to accumulate is Raf, occurring exclusively during exposure to a myriad of abiotic stresses $[10,15]$. In mature Arabidopsis seeds, however, both Raf and Sta accumulate [16-18]. Little is known of RS or their contribution to RFO physiology in Arabidopsis, despite comprehensive identification and characterisation of the 10 GolS genes in this plant $[10,15]$. Using a reversegenetic approach, some indirect evidence points to RS5 being a true RS [14]. In that study, a single T-DNA lossof-function mutant was shown to lack Raf in the leaves after $14 \mathrm{~d}$ of cold treatment at $4^{\circ} \mathrm{C}$, suggesting $R S 5$ to be involved in cold stress-induced Raf accumulation. The gene was neither functionally identified nor were its gene expression, enzyme activity or temporal Raf accumulation during the $14 \mathrm{~d}$ treatment determined. However, in a separate study significant increases and decreases of $R S 5$ transcripts were reported to occur in Arabidopsis leaves subjected to cold acclimation and deacclimation, respectively [19]. High salinity $(150 \mathrm{mM} \mathrm{NaCl})$ and abscisic acid (ABA, $25 \mu \mathrm{M})$ treatments would also appear to result in an increase of $R S 5$ transcripts [20]. In that study, although transcripts increased under both treatments, Raf only accumulated under high salinity and no loss-of-function mutant for RSS was analysed.

In the present work, we further characterised $R S 5$ as a bona fide RS by heterologous expression and functional identification in E. coli. We also characterised in vivo RS activity and Raf accumulation against two additional T-DNA loss-of-function mutants (rs 5-1 and 5-2) following (i) cold-stress $\left(4^{\circ} \mathrm{C}\right)$, (ii) water deficit, (iii) high salinity (100 $\mathrm{mM} \mathrm{NaCl})$, (iv) methyl viologen (MV)-induced oxidative stress $(25 \mu \mathrm{M})$, and (v) heat shock $\left(30^{\circ} \mathrm{C}\right)$. Surprisingly, the RS activity of $R S 5$ encompassed all of these different abiotic stresses with both mutants showing no RS activity and failing to accumulate any Raf in the leaves. Our findings firmly place RS5 (At5g40390) as the only RS in Arabidopsis leaves orchestrating abiotic stress-induced Raf accumulation.

\section{Results}

Crude extracts from E. coli heterologously expressing RS5 produce Raf

The RS5 cDNA was cloned into the pPROEX HTc vector and heterologously expressed in E. coli (BL21, codon plus). When incubated with $50 \mathrm{mM}$ Suc and $5 \mathrm{mM}$ Gol at pH 7.5, crude extracts from E. coli cultures induced for recombinant protein expression with isopropyl $\beta$-D-1-thiogalactopyranoside (IPTG; $1 \mathrm{mM}$, $37^{\circ} \mathrm{C}, 4 \mathrm{~h}$ ) were clearly able to synthesise a compound which eluted at the same retention time as a commercial Raf standard (Figure 1, lower chromatogram). This was contrary to crude extracts from $E$. coli cultures transformed with the pPROEX HTc vector (Figure 1, upper chromatogram). The identity of the putative Raf produced by the recombinant $R S 5$ ( $\operatorname{Raf}^{\mathrm{R}}$, Figure $2 \mathrm{~B}$ ) was confirmed by collecting the corresponding fractions after HPLC separation and hydrolysing them with an acid $\alpha$-Gal. Identical to a commercial Raf standard ( $\mathrm{Raf}^{\mathrm{St}}$, Figure $\left.2 \mathrm{~A}\right), \mathrm{Raf}^{\mathrm{R}}$ was hydrolysed to Suc and Gol in a 1:1 mole ratio (Figures $2 \mathrm{~A}$ and B). Crude extracts containing recombinant RS5 were also tested for alkaline $\alpha$-Gal activity in the presence of $50 \mathrm{mM}$ Raf at pH 7.5. No such activity was detected (Additional file 1: Figure S1), precluding RS5 as an alkaline $\alpha$-Gal.

\section{Seeds from $r$ s 5-1 and 5-2 plants show reduced Raf concentrations}

Water-soluble carbohydrates (WSCs) were extracted from the seeds of mature wild-type and the $r s$ 5-1 and 5-2 mutants, and analysed by HPLC-PAD (Figure 3). The only RFOs present in wild-type seeds were Sta $\left(1.24 \pm 0.076 \mathrm{mg} \mathrm{g}^{-1} \mathrm{DW}\right)$ and Raf $\left[\left(0.62 \pm 0.034 \mathrm{mg} \mathrm{g}^{-1}\right.\right.$ DW). These RFOs were also present in seeds from $r s$ 5-1 and 5-2 [Sta $\left(1.11 \pm 0.11\right.$ and $1.24 \pm 0.04 \mathrm{mg} \mathrm{g}^{-1}$ DW, respectively)] and Raf $(0.34 \pm 0.04$ and $0.35 \pm$ $0.027 \mathrm{mg} \mathrm{g}^{-1} \mathrm{DW}$, respectively)]. Raf concentrations were reduced by about half in the seeds of both RS5 mutants. Gol hyper-accumulated almost 3-fold in seeds from the RS5 mutants, occurring at concentrations of $0.52 \pm 0.051$ and $0.54 \pm 0.026 \mathrm{mg} \mathrm{g}^{-1} \mathrm{DW}$, respectively. Like the Sta concentrations, those of Suc were about equal in all seed types $(9.84 \pm 0.066,8.32 \pm 0.92$ and $10.05 \pm 0.27 \mathrm{mg} \mathrm{g}^{-1} \mathrm{DW}$ for wild-type, $r s 5-1$ and 5-2, respectively). 


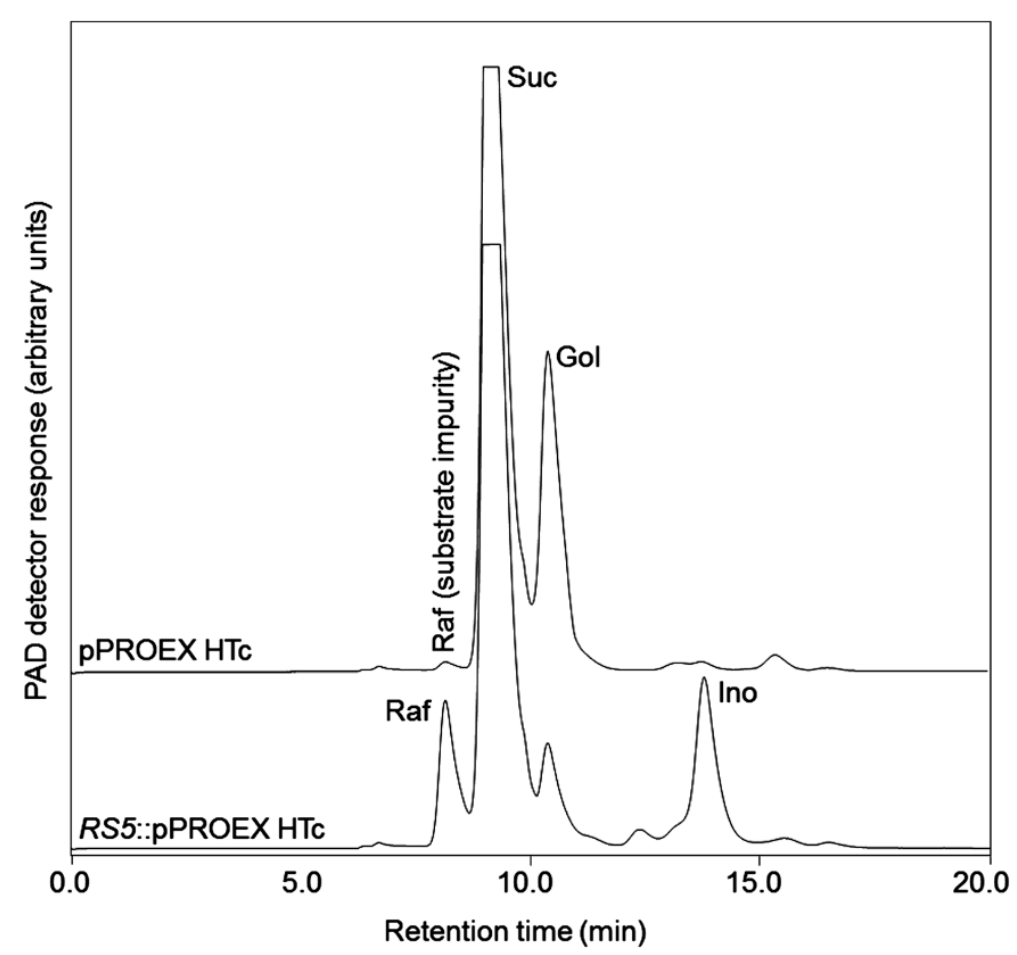

Figure 1 RS activity in crude extracts from E. coli transformed with RS5:pPROExHTc (lower chromatogram). Crude extracts were incubated with $100 \mathrm{mM}$ Suc and $10 \mathrm{mM}$ Gol at pH 7.5 for $1 \mathrm{~h}$. The empty vector control, pPROEx HTc, did not show any RS activity (upper chromatogram). Raf, raffinose (7.2 min); Suc, sucrose ( $8.8 \mathrm{~min})$; Gol, galactinol (11.2 min); Ino, myo-inositol (13.9 min). The Raf biosynthetic reaction yields Ino consequent to the transfer of a galactose moiety from Gol to Suc.

Crude extracts from the leaves of $r s$ 5-1 and 5-2 mutants are deficient in RS activity under multiple abiotic stresses To further characterise RS5 loss-of-function, we reproduced the cold stress experiment previously described [14], using the two additional T-DNA insertion mutants, rs 5-1 and 5-2. Desalted crude enzyme extracts were incubated with either $5 \mathrm{mM}$ UDP-Gal and $50 \mathrm{mM}$ Ino (GolS activity) or $100 \mathrm{mM}$ Suc and $10 \mathrm{mM}$ Gol (RS activity) at $\mathrm{pH} 7.5$.

While wild-type plants showed a clear transcriptional induction of $R S 5$ after $24 \mathrm{~h}$ of cold stress at $4^{\circ} \mathrm{C}$, the leaves of the RS5 mutants were transcript deficient (Figure $4 \mathrm{~A}$ ).
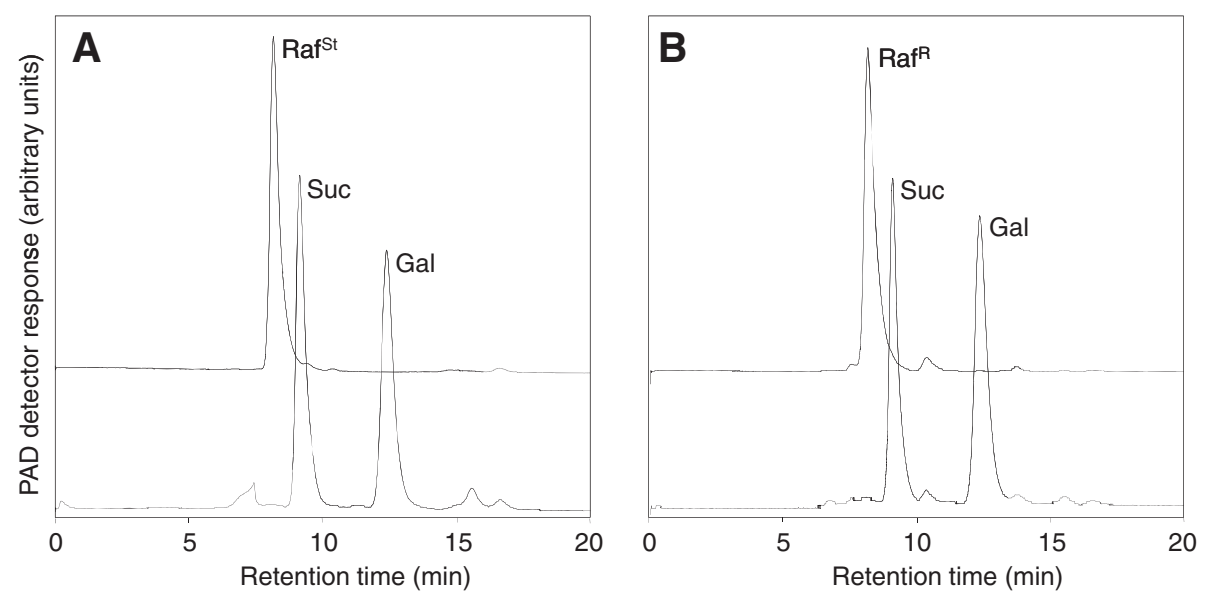

Figure 2 HPLC-PAD chromatograms confirming the identity of Raf $\left(\operatorname{Raf}^{\mathrm{R}}\right)$ produced by recombinant RS5. A, Fractions representing $40 \mathrm{nmol}$ of a commercial Raf standard (Raf ${ }^{5 t}$ ) were collected after separation by HPLC, hydrolysed with a fungal (Aspergillus niger) acid a-Gal and rechromatographed. B, Fractions representing Raf ${ }^{R}$ were collected from RS enzyme activity assays after separation by HPLC, hydrolysed as above and rechromatographed. Raf, raffinose (8.2 min); Suc, sucrose (9.2 min); Gal, galactose (12.4 min). 

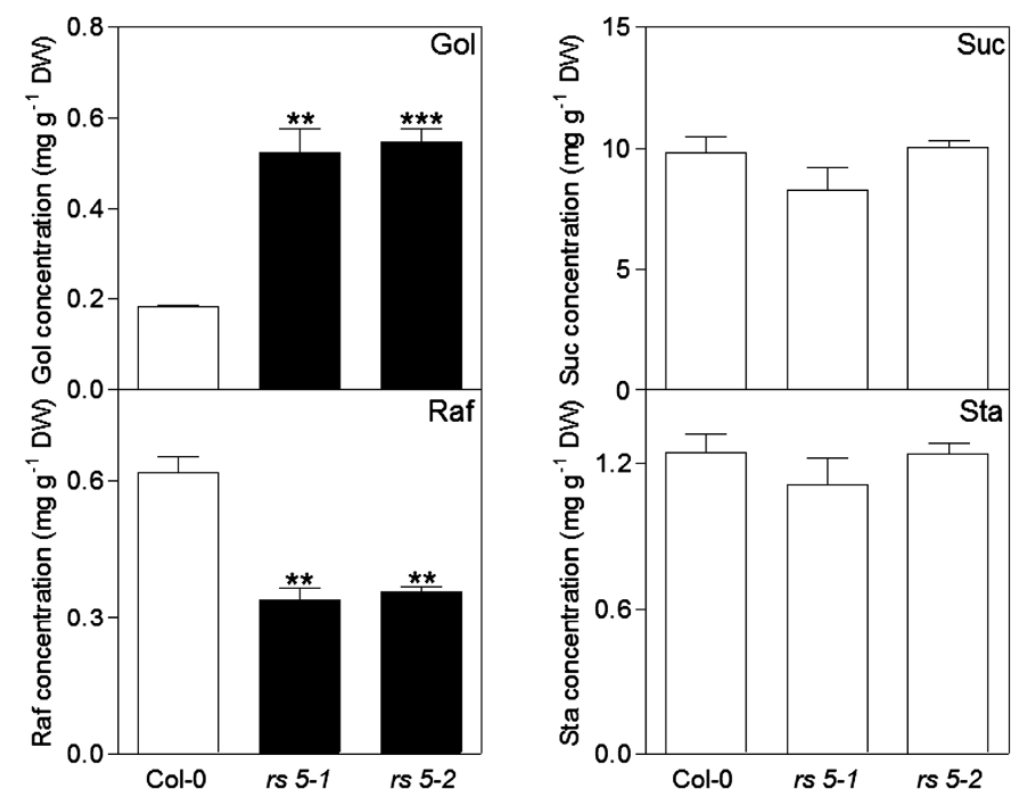

Figure 3 Water-soluble carbohydrates in seeds of Arabidopsis wild-type (Col-0) and $r s$ 5-1 and 5-2 mutant plants. Gol, galactinol; Suc, sucrose; Raf, raffinose; Sta, stachyose. Values are the means \pm SE of three independent replicates. Statistical significance of a two-tailed $t$-test is represented by stars (Gol, ${ }^{* *} \mathrm{p}<0.002$, ${ }^{* * *}$ and $\mathrm{p}<0.0002$; Raf, ${ }^{* *} \mathrm{p}<0.003$ and 0.002 for $\mathrm{rs} 5-1$ and $5-2$, respectively).

Further, when GolS activity was measured under these stress conditions, a clear and comparable increase over the first $12 \mathrm{~h}$ of cold stress was measured in the leaves of both wild-type and the RS5 mutant plants. Thereafter, GolS activity remained constant until $24 \mathrm{~h}$ of stress and declined steadily at $7 \mathrm{~d}$ and $14 \mathrm{~d}$ of stress (Figure 4B). RS activity in the leaves of wild-type plants increased linearly over the stress period from about $0.46 \pm 0.046$ to $1.86 \pm 0.138$ nkat $\mathrm{g}^{-1} \mathrm{DW}$ after $14 \mathrm{~d}$ of stress at $4^{\circ} \mathrm{C}$. Conversely, the leaves of both $r$ 5-1 and 5-2 plants showed only trace activities $\left(0.11 \pm 0.061\right.$ and $0.15 \pm 0.044$ nkat $g^{-1} \mathrm{DW}$, respectively) which remained unchanged over the duration of the stress (Figure 4C).

Under a battery of abiotic stresses, including water deficit, high salinity (100 $\mathrm{mM} \mathrm{NaCl}), \mathrm{MV}$-induced oxidative stress, and heat shock $\left(30^{\circ} \mathrm{C}\right)$, RS activity in the leaves of wild-type plants increased (Table 1). Conversely, either trace activities or no RS activity was detected in the leaves of the rs 5-1 and 5-2 mutants under the same stress conditions.

The leaves of rs 5-1 and 5-2 mutants are deficient in Raf under multiple abiotic stresses

HPLC-PAD analyses of total leaf WSCs from Col-0 and RS5 mutant plants demonstrated that Raf accumulated in Col-0 leaves under conditions of cold stress, water deficit, high salinity, MV-induced oxidative stress and heat shock. This Raf increase was variable, ranging from a 9-fold increase (about $3 \mathrm{mg} \mathrm{g}^{-1} \mathrm{DW}, 3 \mathrm{~h}, 25 \mu \mathrm{M} \mathrm{MV}$ ) to a 121-fold increase ( $40 \mathrm{mg} \mathrm{g}^{-1} \mathrm{DW}, 14 \mathrm{~d}, 4^{\circ} \mathrm{C}$ ). Conversely, the leaves of rs 5-1 and 5-2 mutants were completely deficient of Raf under the same stress conditions (Table 2).

\section{Discussion}

RS5 is not the only RS gene in Arabidopsis

Recent reports provide conflicting evidence suggesting the existence of either a single $[R S 5 ; 6]$ or six $[R S-1$ to $-6 ; 10]$ $\mathrm{RS}$ isoform/s occurring in Arabidopsis. We have recently discounted RS2 (At3g57520/ATSIP2) as a RS, based on functional expression of the cDNA [13]. In that study, we demonstrated that ATSIP2, when expressed in Sf9 insect cells, lacked any RS activity, but rather showed a distinct hydrolase activity with a preference for Raf as a substrate, identifying ATSIP2 as a genuine alkaline $\alpha-G a l$. By heterologously expressing the RS5 cDNA in E. coli we could demonstrate, in vitro, that crude extracts containing recombinant RS5 synthesised Raf and presented no $\alpha$-Gal activity (on Raf, Additional file 1: Figure S1), confirming that RS5 encodes for a genuine RS.

We hypothesised that if RS5 was the sole Arabidopsis RS as previously suggested [6] then mature seeds from the rs 5-1 and 5-2 mutants would show complete ablation of Raf (and possibly Sta) accumulation. It is well reported that, apart from Suc, mature Arabidopsis seeds accumulate substantial quantities of RFOs [mainly Raf and Sta; 16, 17, 18]. Seeds of both $r s$ 5-1 and 5-2 mutants showed reduced Raf concentrations to about $50 \%$ of seeds from wild-type plants. This still represented concentrations of about $0.35 \mathrm{mg} \mathrm{g}^{-1} \mathrm{DW}$, for $r$ s $5-1$ and 5-2 seeds (Figure 3 ). The concentrations of the other 

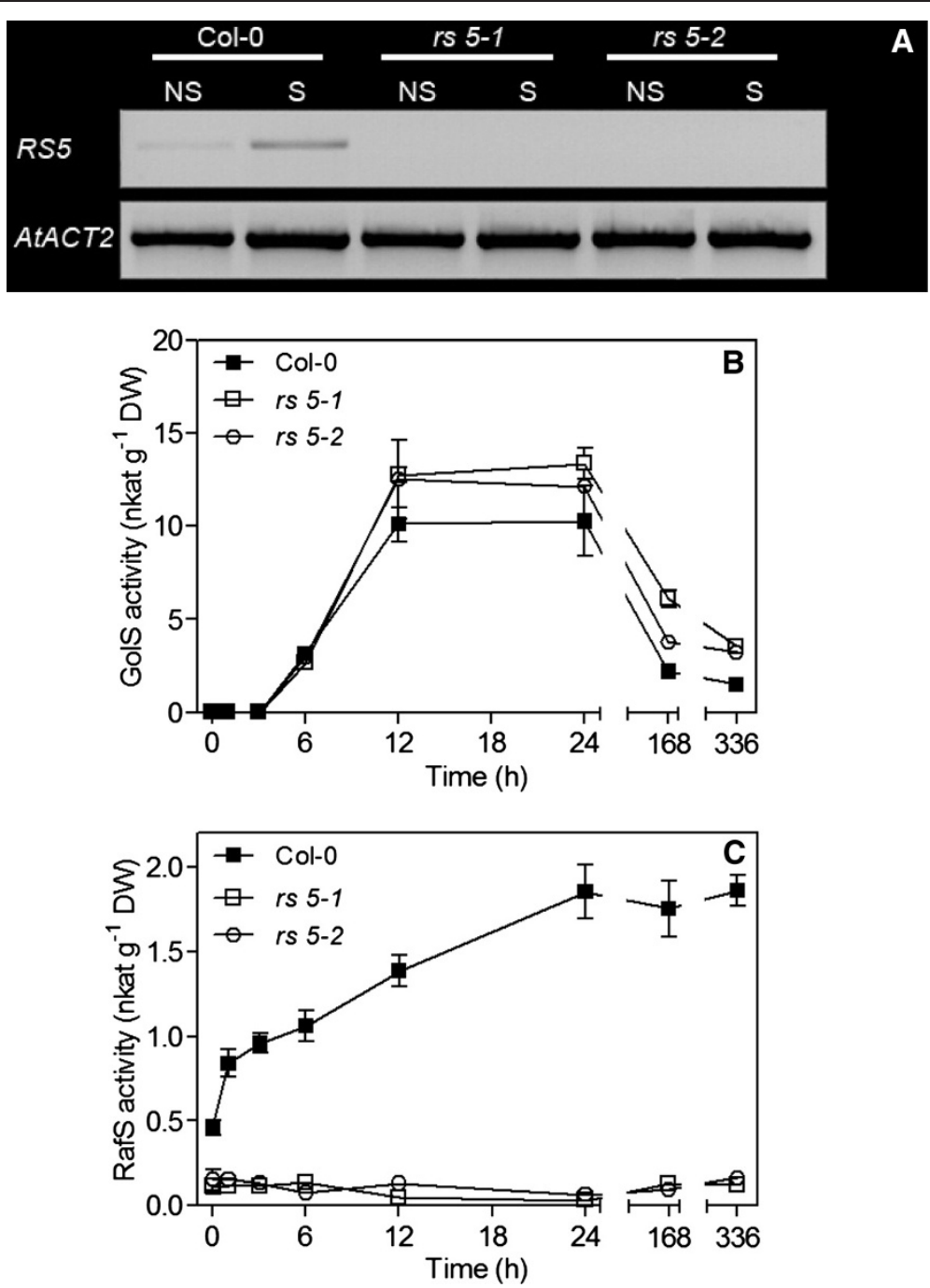

Figure 4 Analyses of $4^{\circ} \mathrm{C}$ cold stressed-leaves from wild-type (Col-0) and RS5 mutants. A, Semi-quantitative PCR of RS5 transcript abundance in the leaves of Col-0, rs 5-1 and 5-2 mutant plants stressed for $24 \mathrm{~h}$. The ACTIN2 gene (ACT2, At3g18780) was used as a constitutively expressed control. B, GolS activity in the leaves of Col-0, rs 5-1 and 5-2 plants stressed for $14 \mathrm{~d}$. C, RS activity in the leaves of Col-0, rs 5-1 and 5-2 plants stressed for $14 \mathrm{~d}$.

Table 1 RS activities in leaves of wild-type (Col-0) and RS5 mutants subjected to various abiotic stresses

\begin{tabular}{|c|c|c|c|c|c|c|c|c|c|c|}
\hline & \multicolumn{2}{|c|}{$4^{\circ} \mathrm{C}$} & \multicolumn{2}{|c|}{ WD } & \multicolumn{2}{|c|}{$\mathrm{NaCl}$} & \multicolumn{2}{|c|}{ MV } & \multicolumn{2}{|c|}{$30^{\circ} \mathrm{C}$} \\
\hline & NS & $S$ & NS & $S$ & NS & $S$ & NS & $S$ & NS & $S$ \\
\hline Col-0 & $0.46 \pm 0.046$ & $1.86 \pm 0.138$ & $0.55 \pm 0.014$ & $1.17 \pm 0.065$ & $0.18 \pm 0.005$ & $0.34 \pm 0.002$ & $0.22 \pm 0.004$ & $0.33 \pm 0.006$ & $0.24 \pm 0.004$ & $0.33 \pm 0.002$ \\
\hline is 5-1 & $0.15 \pm 0.044$ & $0.16 \pm 0.028$ & $0.16 \pm 0.006$ & $0.14 \pm 0.002$ & n.d. & n.d. & n.d. & n.d. & n.d. & n.d. \\
\hline rs 5-2 & $0.11 \pm 0.061$ & $0.12 \pm 0.025$ & $0.17 \pm 0.009$ & $0.16 \pm 0.002$ & n.d. & n.d. & n.d. & n.d. & n.d. & n.d. \\
\hline
\end{tabular}

Assays were conducted with desalted leaf crude extracts incubated with $100 \mathrm{mM}$ Suc and $10 \mathrm{mM}$ Gol at pH 7.5 for $1 \mathrm{~h}$. NS, non-stressed; S, stressed (as per Materials and Methods); $4^{\circ} \mathrm{C}$, cold-stressed; WD, water deficit-stressed; $\mathrm{NaCl}$, salt-stressed; $\mathrm{MV}$, methyl viologen-stressed; $30^{\circ} \mathrm{C}$, heat-stressed. Values in bold represent increased RS activities in stressed as compared to non-stressed leaves. Values are the means \pm SE of three independent replicates and represent RS activities expressed in nkat $\mathrm{g}^{-1} \mathrm{DW}$. 
Table 2 Raf concentrations in leaves of wild-type (Col-0) and RS5 mutants subjected to various abiotic stresses

\begin{tabular}{lcccccc}
\hline & NS & $\mathbf{4}^{\circ} \mathrm{C}$ & WD & $\mathrm{NaCl}$ & MV & $30^{\circ} \mathrm{C}$ \\
\hline Col-0 & $0.33 \pm 0.012$ & $\mathbf{4 0 . 0 0 \pm 1 . 4 8 8}$ & $\mathbf{1 1 . 0 0 \pm 0 . 2 2 1}$ & $\mathbf{1 7 . 0 0 \pm 1 . 5 7 7}$ & $\mathbf{3 . 0 3} \pm \mathbf{0 . 6 0 3}$ & $\mathbf{1 0 . 1 5 \pm 0 . 6 2 2}$ \\
rs 5-1 & n.d. & n.d. & n.d. & n.d. & n.d. & n.d. \\
rs 5-2 & n.d. & n.d. & n.d. & n.d. & n.d. & n.d. \\
\hline
\end{tabular}

NS, non-stressed; S, stressed (as per Materials and Methods); $4^{\circ} \mathrm{C}$, cold-stressed; WD, water deficit-stressed; $\mathrm{NaCl}$, salt-stressed; $\mathrm{MV}$, methyl viologen-stressed; $30^{\circ} \mathrm{C}$, heat-stressed. Values in bold represent increased Raf in stressed as compared to non-stressed leaves. Values are the means \pm SE of three independent replicates and represent Raf concentrations expressed as $\mathrm{mg} \mathrm{g}^{-1} \mathrm{DW}$.

major seed WSCs, Sta and Suc, were comparable between the mutants and those of wild-type plants (Figure 3). These observations argue for the existence of at least one other, as yet unidentified, RS in Arabidopsis which is responsible for Raf accumulation during seed development. Importantly, we could allocate an additional physiological role to RS5 in Raf accumulation during seed development, apart from its already reported role in Raf accumulation in Arabidopsis leaves during cold stress [14].

RS5 is the only RS gene responsible for Raf accumulation in leaves during abiotic stress

To further investigate the existence of other putative $R S$ genes in vivo, 5-week old soil-grown wild-type and mutant plants were subjected to a battery of abiotic stresses (cold stress, water deficit, high salinity, heat shock and MV-induced oxidative stress). All of these stress conditions result in the accumulation of Raf in the leaves of Arabidopsis and have been shown to differentially upregulate various GolS isoforms in leaves [10,14,15,21]. Surprisingly, while wild-type plants accumulated Raf in the leaves under all conditions tested, both RS5 mutants failed to do so in their leaves (Table 2) suggesting that At5g40390 is the only RS, in leaves, responsible for abiotic stress-induced Raf accumulation.

Further evidence was obtained by measuring the total extractable RS activity in the leaves of wild-type and RS5 mutant plants during exposure to the stresses stated above. Under all conditions, an increase in RS activity was measured in leaves of stressed wild-type plants, while leaves of $r s$ 5-1 and 5-2 mutants presented either trace (cold stress) or no measurable RS activities (Table 1). During our experimentation, we observed distinct variations in RS activity between independent wildtype control plants (unstressed) despite the controlled growth conditions described. The reason for this finding is unclear, but we propose that it may be due to subtle physiological differences between the plants used in these independent experiments.

The ablation of stress-induced RS activity in the rs 5-1 and 5-2 mutants is astonishing, particularly given that six of the 10 Gols genes in Arabidopsis have been implicated in abiotic stress-related RFO metabolism [10,15]. Furthermore, six putative abiotic stress inducible RS genes have recently been reported in Arabidopsis [designated $R S-1$ to -6 , 10]. In the present study using a reverse genetic approach, we describe RS5 (At5g40390) as being the sole abiotic stress-induced RS in Arabidopsis leaves. Hence, the putative RS-1, -3, -4 and -6 (At1g55740, At4g01265, At4g01970 and At5g20250, respectively) may be precluded as abiotic stress-inducible RSs.

As a consequence of $R S 5$ loss-of-function, the leaves of rs 5-1 and 5-2 mutant plants subjected to abiotic stresses hyper-accumulated Gol but not Raf. The GABIKAT T-DNA insertion mutant previously reported also hyper-accumulated $\mathrm{Gol}$ in the leaves after cold stress [4 $\left.{ }^{\circ} \mathrm{C}, 14 \mathrm{~d} ; 15\right]$. The role of $\mathrm{Gol}$ as a legitimate stress protectant has been largely overlooked, perhaps because the occurrence of Gol is always linked to the presence of Raf (the most widely reported WSC with protective functions). Our findings clearly demonstrate that RS5 loss-of-function mutants provide a Raf-free biological system during exposure to abiotic stress, potentially providing a means to analyse a functional role for Gol in stress protection. Experiments are currently underway with a particular focus on dissecting the possible protective effects that Gol hyper-accumulation may facilitate in the absence of Raf.

\section{Conclusions}

Using a reverse genetic approach RS5 (At5g40390) has previously only been characterised as a low temperature-induced RS contributing to Raf accumulation in Arabidopsis leaves. Using two additional loss-of-function mutants we could demonstrate further that RS5 (i) is the sole RS responsible for Raf accumulation in Arabidopsis leaves exposed to water deficit, high salinity, MV-induced oxidative stress and heat shock and, (ii) also functions in Raf accumulation in Arabidopsis seeds. Collectively, this work unambiguously demonstrates $R S 5$ is the only RS responsible for Raf accumulation in Arabidopsis leaves during abiotic stress and precludes the existence of five other putative abiotic stress-inducible RSs recently described on the basis of sequence homology. 


\section{Methods}

Plant material and abiotic stress treatments

The RS5 mutants (rs 5-1 and 5-2) in the Col-0 background were obtained from the SALK collection (SALK_049583 and_085989, respectively). The mutants carry a T-DNA insert in the second intron of At5g40390. Homozygous mutants were identified by PCR using two different primer pairs: the At5g40390 wild-type allele was amplified with the primers rs 5-1 (fwd 5' CTCTTCTTGAAGGCTCCTTCC, rev 5 ATGACATCAACTTTAACGCCG) and rs 5-2 (fwd 5 ATGGAACTCAGCACAAGGATG, rev 5 'TTATTGAAA TCCTCACACC). The mutant allele was amplified with the SALK Lb1.3 primer (5 TTTTGCCGATTTCGGA $\mathrm{AC)}$ and either the $r s$ 5-1 or 5-2 reverse primer, respectively. Wild-type plants used in this study represented a pool (3) of individual plants which genotyped as wild-type in the screen described above.

Following seed stratification $\left(48 \mathrm{~h}, 4^{\circ} \mathrm{C}\right)$, Arabidopsis plants were propagated in soil (Einheitserde, type ED73, Gebr. Patzer GmbH \& Co. KG, Schopfheim, Germany) in a controlled environment chamber $(8 \mathrm{~h}$ light, $30 \mu \mathrm{mol}$ photons $\mathrm{m}^{-2} \mathrm{~s}^{-1}, 22^{\circ} \mathrm{C}, 16 \mathrm{~h}$ dark, $\left.60 \% \mathrm{RH}\right)$. Five-weekold plants were used for abiotic stress treatments as follows. Experiments were conducted twice, using 4 pools of 6 plants (24 plants) per experiment.

(i) cold stress: plants were transferred into an acclimation chamber with identical settings to those listed above but with a constant temperature of $4^{\circ} \mathrm{C}$, for a period of $14 \mathrm{~d}$; (ii) high salinity was imposed by irrigating soil with $150 \mathrm{ml}$ of $\mathrm{NaCl}$ solution (25 mM, after $24 \mathrm{~h}$ $50 \mathrm{mM}$ and $24 \mathrm{~h}$ thereafter $100 \mathrm{mM}$ ); (iii) water deficit: soil was passed through a sieve $(0.5 \times 0.5 \mathrm{~cm}$ mesh size $)$ to remove large detritus and $60 \mathrm{~g}$ was weighed into pots prior to seed sowing. The pots were sub-irrigated twice weekly until plants reached the desired growth stage (5-week-old). Water deficit was subsequently imposed by withholding water until leaves showed the first visible signs of leaf wilting, typically occurring between 7 and 9 d under our growth conditions, (iv) oxidative stress was imposed as previously described [10], with minor modifications. Leaves were liberally sprayed with $25 \mu \mathrm{M} \mathrm{MV}$ (paraquat) followed by a $3 \mathrm{~h}$ exposure to high lightintensity $\left(700 \mu \mathrm{mol}\right.$ photons $\left.\mathrm{m}^{-2} \mathrm{~s}^{-1}\right)$; (v) heat shock was imposed by transferring plants to $30^{\circ} \mathrm{C}$ for $6 \mathrm{~h}$.

\section{RNA isolation and semiquantitative PCR (sqPCR)}

Total RNA was extracted from leaves using the RNeasy mini kit (Qiagen, Hombrechtikon, Switzerland), following the manufacturer's instructions. The cDNA template for sqPCR were obtained by reverse transcription of $1 \mu \mathrm{g}$ total RNA with an oligo $\left(\mathrm{dT}_{15}\right)$ primer and the MMLV reverse transcriptase (Promega AG, Dübendorf, Switzerland) following the manufacturer's instructions.
The sqPCR was carried out in $50 \mu \mathrm{l}$ containing $5 \mu \mathrm{l}$ cDNA, $0.5 \mathrm{mM}$ of each dNTP, and $0.5 \mu \mathrm{mol}$ of each primer, 1X PCR buffer and 1.25 U GoTaq DNA polymerase (Promega), at a primer annealing temperature of $56^{\circ} \mathrm{C}$ for 24 cycles. The number of cycles chosen for the sqPCR was determined to occur in the linear range of the constitutively expressed ACTIN2 gene (ACT2, At3g18780). The following primer pairs were used to amplify a $1 \mathrm{~Kb}$ fragment of the corresponding cDNAs ACTIN2: ACT2 $2_{\text {fwd }}$ 5'ATGGCTGAGGCTGATGATAT, $A C T 2_{r e v}$ 5'TTAGAAACATTTTCTGTGAACGAT; RS5: $R S 5_{\text {fwd }} 5$ ATGGCTTCGCCGTGTTTGACC and $R S 5_{\text {rev }}$ 5' CGGAGCTTCAGGACGGAGAC.

\section{Heterologous expression of At5g40390 in E. coli}

Total RNA was isolated from the leaves of cold-stressed $\left(4^{\circ} \mathrm{C}, 14 \mathrm{~d}\right)$ Col-0 Arabidopsis plants using the Plant RNeasy kit (Qiagen AG, Hombrechtikon, Switzerland). The cDNA template for high fidelity PCR of the At5g40390 open reading frame (ORF) was obtained by reverse transcribing $1 \mu \mathrm{g}$ total RNA with an oligo $\left(\mathrm{dT}_{15}\right)$ primer and $\mathrm{M}-\mathrm{MLV}\left(\mathrm{H}^{-}\right)$reverse transcriptase (Promega AG, Dübendorf, Switzerland) following the manufacturer's protocol. The high fidelity PCR was conducted with $2 \mu$ f first strand cDNA using the Expand High Fidelity PCR kit (Roche) following the manufacturer's instructions. The primer pair amplified the entire $2.48 \mathrm{kB}$ ORF of At5g40390 ( RS5 $_{f w d} 5$ 'ATGGCTTCGCCGTGT TTGACC and $R S 5_{r e v}$ 5' CTAAAACAAATACTGAATA GAAGACAAACC). The resultant amplicon was cloned into the pGEMT-Easy vector (Promega) and subcloned into the pPROEx HTc vector (Invitrogen) using the NotI restriction endonuclease. This construct (RS5::pPROExHTc) was transformed via standard heat shock procedure, into $E$. coli (BL21 Codon Plus, Stratagene).

Induction of recombinant RS5 expression and crude extract preparations were conducted as previously described [22]. Aliquots $(25 \mu \mathrm{l})$ of crude extracts were assayed for RS activity in a $50 \mu \mathrm{l}$ final volume containing $25 \mu \mathrm{l}$ assay buffer (50 mM HEPES-KOH, pH 7.5, $100 \mathrm{mM}$ Suc, $10 \mathrm{mM}$ Gol). Assays were incubated for $1 \mathrm{~h}$ at $30^{\circ} \mathrm{C}$ and subsequently desalted and analysed by HPLC-PAD as previously described [4,13,22,23]. Control reactions represented crude extracts from cell cultures transformed with the empty pPROExHTc vector and processed as outlined above.

To confirm that heterologous RS5 actually produced Raf, fractions of enzyme assay reactions were collected after HPLC separation and digested with a fungal (Aspergillus niger) acid $\alpha-G a l$, as previously described [22]. Further, to confirm that RS5 did not display an alkaline $\alpha$-Gal activity, crude extracts were incubated in the presence of $50 \mathrm{mM}$ Raf [13]. 


\section{Enzyme extractions, GolS and RS activity assays}

Freshly harvested Arabidopsis leaf material (200 mg) was ground in $400 \mu \mathrm{l}$ of chilled extraction buffer [50 mM HEPES/KOH, pH 7.5, $5 \mathrm{mM} \mathrm{MgCl}_{2}, 1 \mathrm{mM}$ EDTA, $20 \mathrm{mM}$ dithiothreitol (DTT), 0.1\% (v/v) Triton $\mathrm{X}$-100, $1 \mathrm{mM}$ benzamidine, $1 \mathrm{mM}$ phenylmethylsulphonyl fluoride (PMSF), $50 \mathrm{mM}$ Na-ascorbate, 2\% (w/v) polyvinylpyrrolidone (PVP)]. Samples were centrifuged at $12,000 \mathrm{x} \mathrm{g}\left(5 \mathrm{~min}, 4^{\circ} \mathrm{C}\right)$. A $200 \mu \mathrm{l}$ aliquot of supernatant was desalted by gel filtration at $1,400 \mathrm{x} g(2 \mathrm{~min}$, $4^{\circ} \mathrm{C}$ ) through $5 \mathrm{ml}$ Sephadex G-25 columns (fine, final bed volume of $3 \mathrm{ml}$ ). Columns were pre-equilibrated with assay buffer (50 mM HEPES/KOH, pH 7.5, $2 \mathrm{mM}$ $\left.\mathrm{MnCl}_{2}, 10 \mathrm{mM} \mathrm{DTT}\right)$. Pre-equilibration was performed twice with $2 \mathrm{ml}$ of assay buffer. Aliquots $(20 \mu \mathrm{l})$ of desalted extract were assayed for GolS activity in a final volume of $40 \mu \mathrm{l}$ containing $20 \mu \mathrm{l}$ assay buffer $(50 \mathrm{mM}$ HEPES-KOH, pH 7.5, $100 \mathrm{mM}$ Ino, $10 \mathrm{mM}$ UDP-Gal) at $30^{\circ} \mathrm{C}$ for $20 \mathrm{~min}$. Similarly, RS activity was assayed at $30^{\circ} \mathrm{C}$ for $60 \mathrm{~min}$ with assay buffer (50 mM HEPES-KOH, pH 7.5, $100 \mathrm{mM}$ Suc, $10 \mathrm{mM} \mathrm{Gol}$ ). To determine the degree of Raf contamination of Suc (substrate impurity), assay buffer was

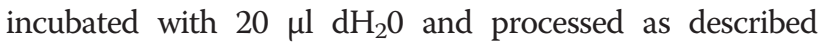
above. Samples were desalted and analysed by HPLC-PAD as previously described [4,22,23]. Enzyme activities were expressed as a measure of dry weight.

\section{WSC extraction}

WSCs were extracted using an ethanol series, as previously described $[4,13,22,23]$, with minor modifications. Ground, freeze-dried Arabidopsis leaf material (100 mg) from 5-week-old soil-grown plants was flash-frozen in liquid $\mathrm{N}_{2}$ and macerated, by hand, using plastic pestle in a $1.5 \mathrm{ml}$ Eppendorf tube. WSCs were extracted twice (per step) in a three-step sequential process, using $1 \mathrm{ml}$ of $80 \%(\mathrm{v} / \mathrm{v}) \mathrm{EtOH}, 50 \%(\mathrm{v} / \mathrm{v}) \mathrm{EtOH}$, and $\mathrm{dH}_{2} \mathrm{O}$, respectively. Extractions were conducted at $80^{\circ} \mathrm{C}$ for $10 \mathrm{~min}$ and the tubes centrifuged at $15,000 \times \mathrm{g}\left(5 \mathrm{~min}, 4^{\circ} \mathrm{C}\right)$. Samples were desalted and analysed by HPLC-PAD as previously described $[4,13,22,23]$.

\section{HPLC-PAD analysis}

Desalted WSC extracts and enzyme assay reactions were analysed and quantified by HPLC-PAD as previously described $[4,13,22,23]$. Briefly, a $\mathrm{Ca}^{2+} / \mathrm{Na}^{+}$-moderated ion partitioning carbohydrate column (Benson BC100, BC200 columns, $7.8 \times 300 \mathrm{~mm}$; Benson Polymeric, Reno, Nevada, USA) was used to separate carbohydrates. Quantification was done using the Chromeleon v6.4 software package (Dionex) against a series of $5 \mathrm{nmol}$ of standard sugars, the concentration of which corresponded to the linear response range of both chromatographic systems.

\section{Additional file}

Additional file 1: Figure S1. HPLC-PAD chromatogram testing alkaline a-galactosidase (PDF $183 \mathrm{~kb}$ )(a-Gal) activity in crude extracts from E. coli transformed with RS5::pPROExHTc. Crude extracts were incubated with $50 \mathrm{mM}$ Raf at pH 7.5 for 1 h. Crude extacts (from Sf9 insect cells) that het erologously expressed ATSIP2 (At3g57520, Peters et al. 2010) were used as a positive control for a-Gal activity. Neither the empty vector control, pPROExHTc, nor RS5::pPROExHTc showed any a-Gal activity. Raf, raffinose (8.2 min); Suc, sucrose (9.4 min); Gal, galactose (12.6 min).

\section{Abbreviations}

RS: Raffinose synthase; Gol: Galactinol; Raf: Raffinose; Sta: Stachyose; GGT: Galactan:galactan galactosyl transferase; a-Gal: a-galactosidase; GolS: Galactinol synthase; ATSIP1/ATSIP2: Arabidopsis thaliana seed imbibition protein 1/2; MV: Methyl viologen; DW: Dry weight.

\section{Competing interests}

The authors declare that they have no competing interests.

\section{Authors' contributions}

$\mathrm{AE}$ conducted the stress experiments and measurements of (i) water-soluble carbohydrates and (ii) enzyme activities. FK participated in design and co-ordination of the study. SP conceived of the study, its design and co-ordination and undertook (i) the heterologous expression in E.coli and (ii) identification of the Arabidopsis mutants. All authors read and approved the final manuscript.

\section{Acknowledgements}

This work was supported by the Swiss National Foundation (grant number 31-116599).

\section{Author details}

'Institute of Plant Biology, Molecular Plant Physiology Division, University of Zürich, Zollikerstrasse 107, Zürich CH-8008, Switzerland. ${ }^{2}$ Institute for Plant Biotechnology, Department of Genetics, Faculty of AgriSciences, Stellenbosch University, Matieland 7602, South Africa. ${ }^{3}$ Present address: Molecular and Systems Toxicology, Department of Pharmaceutical Sciences, University of Basel, Klingelbergstrasse 50, Basel CH-4056, Switzerland.

Received: 29 August 2013 Accepted: 9 December 2013

Published: 20 December 2013

\section{References}

1. Bachmann M, Keller F: Metabolism of the raffinose family oligosaccharides in leaves of Ajuga reptans L. (inter- and intracellular compartmentation). Plant Physiol 1995, 109:991-998.

2. Haab Cl, Keller F: Purification and characterization of the raffinose oligosaccharide chain elongation enzyme, galactan:galactan galactosyltransferase (GGT), from Ajuga reptans leaves. Physiologia Plant 2002, 114:361-371.

3. Tapernoux-Lüthi EM, Böhm A, Keller F: Cloning, functional expression, and characterization of the raffinose oligosaccharide chain elongation enzyme, galactan:galactan galactosyltransferase, from common bugle leaves. Plant Physiol 2004, 134:1377-1387.

4. Peters S, Keller F: Frost tolerance in excised leaves of the common bugle (Ajuga reptans L.) correlates positively with the concentrations of raffinose family oligosaccharides (RFOs). Plant Cell Environ 2009, 32:1099-1107.

5. Gilbert GA, Wilson C, Madore MA: Root-zone salinity alters raffinose oligosaccharide metabolism and transport in Coleus. Plant Physio/ 1997, 115:1267-1276.

6. Dierking EC, Bilyeu KD: Association of a soybean raffinose synthase gene with low raffinose and stachyose seed phenotype. Plant Gen 2008, 1:135-145.

7. Peterbauer $T$, Lahuta LB, Blöchl A, Mucha J, Jones DA, Hedley $C L$, Gòrecki RJ, Richter A: Analysis of the raffinose family oligosaccharide pathway in pea seeds with contrasting carbohydrate composition. Plant Physiol 2001, 127:1764-1772. 
8. Sui XL, Meng FZ, Wang HY, Wei YX, Li RF, Wang ZY, Hu LP, Wang SH, Zhang ZX: Molecular cloning, characteristics and low temperature response of raffinose synthase gene in Cucumis sativus L. J Plant Physiol 2012, 169:1883-1891.

9. Li S, Li T, Kim W-D, Kitaoka M, Yoshida S, Nakajima M, Kobayashi H: Characterization of raffinose synthase from rice (Oryza sativa L. var. Nipponbare). Biotech Letters 2007, 29:635-640.

10. Nishizawa A, Yabuta Y, Shigeoka S: Galactinol and raffinose constitute a novel function to protect plants from oxidative damage. Plant Physiol 2008, 147:1251-1263.

11. Maruyama K, Takeda M, Kidokoro S, Yamada K, Sakuma Y, Urano K, Fujita M, Yoshiwara K, Matsukura S, Morishita Y, et al: Metabolic pathways involved in cold acclimation identified by integrated analysis of metabolites and transcripts regulated by DREB1A and DREB2A. Plant Physiol 2009, 150:1972-1980.

12. Wu X, Kishitani S, Ito $Y$, Toriyama K: Accumulation of raffinose in rice seedlings overexpressing OsWRKY11 in relation to desiccation tolerance. Plant Biotech 2009, 26:431-434.

13. Peters S, Egert A, Stieger B, Keller F: Functional identification of Arabidopsis ATSIP2 (At3g57520) as an alkaline a-galactosidase with a substrate specificity for raffinose and an apparent sink-specific expression pattern. Plant Cell Physiol 2010, 51:1815-1819.

14. Zuther E, Buchel K, Hundertmark M, Stitt M, Hincha DK, Heyer AG: The role of raffinose in the cold acclimation response of Arabidopsis thaliana. FEBS Lett 2004, 576:169-173.

15. Taji T, Ohsumi C, luchi S, Seki M, Kasuga M, Kobayashi M, YamaguchiShinozaki K, Shinozaki K: Important roles of drought- and cold-inducible genes for galactinol synthase in stress tolerance in Arabidopsis thaliana. Plant J 2002, 29:417-426.

16. Ooms J, Leon-Kloosterziel KM, Bartels D, Koornneef M, Karssen CM: Acquisition of desiccation tolerance and longevity in seeds of Arabidopsis thaliana (a comparative study using abscisic acid-insensitive abi3 mutants). Plant Physiol 1993, 102:1185-1191.

17. Bentsink L, Alonso-Blanco C, Vreugdenhil D, Tesnier K, Groot SPC, Koornneef $\mathrm{M}$ : Genetic analysis of seed-soluble oligosaccharides in relation to seed storability of Arabidopsis. Plant Physiol 2000, 124:1595-1604.

18. Nishizawa-Yokoi A, Yabuta Y, Shigeoka S: The contribution of carbohydrates including raffinose family oligosaccharides and sugar alcohols to protection of plant cells from oxidative damage. Plant Signal Behavior 2008, 3:1016-1018.

19. Oono Y, Seki M, Satou M, lida K, Akiyama K, Sakurai T, Fujita M, YamaguchiShinozaki K, Shinozaki K: Monitoring expression profiles of Arabidopsis genes during cold acclimation and deacclimation using DNA microarrays. Funct Integr Genomics 2006, 6:212-234.

20. Kempa S, Krasensky J, Dal Santo S, Kopka J, Jonak C: A central role of abscisic acid in stress-regulated carbohydrate metabolism. PLOS ONE 2008, 3:e3935.

21. Panikulangara TJ, Eggers-Schumacher G, Wunderlich M, Stransky H, Schöffl F: Galactinol synthase1. A novel heat shock factor target gene responsible for heat-induced synthesis of raffinose family oligosaccharides in Arabidopsis. Plant Physiol 2004, 136:3148-3158.

22. Peters S, Mundree SG, Thomson JA, Farrant JM, Keller F: Protection mechanisms in the resurrection plant Xerophyta viscosa (Baker): both sucrose and raffinose family oligosaccharides (RFOs) accumulate in leaves in response to water deficit. J Exp Bot 2007, 58:1947-1956.

23. Egert A, Peters S, Guyot C, Stieger B, Keller F: An Arabidopsis T-DNA insertion mutant for galactokinase (AtGALK, At3g06580) hyperaccumulates free galactose and is insensitive to exogenous galactose. Plant Cell Physiol 2012, 53:921-929.

doi:10.1186/1471-2229-13-218

Cite this article as: Egert et al:: Abiotic stress-induced accumulation of raffinose in Arabidopsis leaves is mediated by a single

raffinose synthase (RS5, At5g40390). BMC Plant Biology 2013 13:218.

\section{Submit your next manuscript to BioMed Central and take full advantage of:}

- Convenient online submission

- Thorough peer review

- No space constraints or color figure charges

- Immediate publication on acceptance

- Inclusion in PubMed, CAS, Scopus and Google Scholar

- Research which is freely available for redistribution 